\title{
The Challenge of Solvency Reform for European Insurers
}

\author{
Philippe Trainar \\ Fédération Française des Sociétés d'Assurance, 26 bvd Haussmann, 75311 Paris Cedex 09, France. \\ E-mail: p.trainar@ffsa.fr
}

The process of the European insurance companies' solvency reform has entered into an extremely active phase. The European Commission drafted a Framework to guide the process, which it amended over the summer of 2005. In parallel with the release of this Framework, the Commission launched three waves of consultations. To understand what is at stake with this reform, it is useful to begin by reviewing the reasons that led the Commission to initiate Solvency II in the first place, upon completion of Solvency I, and the conditions under which the process should be conducted. Then, we will turn to the principal orientations of the reform, with particular emphasis on six of them. Finally, we discuss seven of the most salient economic and financial issues at this point in the discussion. The fact that the Commission's work was not preceded by in-depth technical work, as was the case for the Basel Committee when it undertook banking solvency reform, gives us some idea of the magnitude of the task facing the Commission, which must not only invent new legislation better adapted to the realities of the European insurance industry, but also resolve a number of technical, economic and financial matters for which little or no consensus exists today.

The Geneva Papers (2006) 31, 169-185. doi:10.1057/palgrave.gpp.2510066

Keywords: Solvency II; European insurers; solvency reform

\section{Why and how to reform the solvency requirements for European insurers}

It may seem strange to embark on the process of reforming European insurance companies' solvency (under the name of Solvency II), when the previous reform (Solvency I) has only just been implemented. To make sense of this decision, let us consider the conditions under which Solvency I was finalized. As the discussion began to extend far beyond the deadline that was initially set, the Commission decided to limit Solvency I to a simple exercise in surface cleaning, and to set a more open-ended agenda for discussing the principles of a new architecture for insurance company solvency. Solvency II is thus the second phase of a reform that began with Solvency I. Below, we examine the philosophical rationale behind this in-depth reform of current solvency regulations, and the importance of carrying out this reform within the framework of a broadly open discussion.

\section{The rationale behind the reform}

A brief reminder of the principles underlying current solvency regulations provides a useful starting point for putting this rationale into perspective. 
(a) The three current pillars of European insurance company solvency

In European directives on the subject, which have been transposed into domestic law, an insurance company's solvency is based on three pillars that together span the balance sheet of an insurance company: the adequacy of its reserves, the quality of its assets, and the minimum required solvency margin.

Reserves that are intended to represent the value of the policyholder obligations underwritten by insurance companies must be adequate. In order to be adequate, they must be enough to compensate policyholders when insured losses occur. Reserves must also be prudent, that is, they must cover not only the average situation that insurance companies face, but also the deviations from this situation, whenever such deviations show a sufficient degree of probability of occurrence. Every country has developed a specific set of rules for determining the adequacy of reserves (redemption or cash value of policies, equalizations reserves, etc.), or they are determined by an independent actuary.

The assets in which the insurer invests policyholder premiums must meet certain quality standards. They must be liquid, that is, it must be possible to realize them when the time comes to pay what is owed to policyholders. They must also provide returns that cover the expected cost of compensation. To this end, they must be diversified, meaning that they must be invested in different asset classes with different risk/return trade-offs (equities, bonds, real estate, derivatives) and they must be dispersed, meaning invested in different counterparties with different credit risk profiles. Depending on the country, these quality assets are either defined within the framework of specific rules (lists of admissible or eligible assets and defined percentage limits) or by way of discretionary regulatory control.

The solvency margin requirement for stand-alone insurance companies, consolidated insurance groups and financial service conglomerates alike, corresponds to the minimum amount of capital deemed necessary to deal with unforeseen risks. Insurance directives define the term very precisely, as a proportion of at-risk capital, reserves or premiums, net of reinsurance. For life insurance, the level is defined as 4 per cent of reserves for contracts denominated in euros, and 1 per cent of at-risk capital for unit-linked contracts. In property-casualty insurance, it is equal to a maximum of 16 per cent of premiums or 23 per cent of reserves. Unlike the American concept of risk-based capital (RBC), assets are not differentially weighted to reflect their risk level.

\section{(b) The limits of current solvency regulations}

Current efforts to reform the European solvency system were inspired by Basel II and the reform of banking solvency requirements. It created a similar need for modernizing the insurance industry, whose solvency regulations had not changed for several decades in Europe. These reforms have also come in for a number of criticisms. Four, in particular, have been heard, both during the Solvency I debate and in recent years. The rules are said to lack harmony, to rely on an overly simplistic approach to the notion of risk, to be insufficiently discriminating when it comes to assessing the real financial condition of the companies measured, and to be unable to capture the reality of insurance groups. 
Given the heterogeneity of the rules applied from one country to the other, the desire for harmonization evident in EU directives is an illusory goal, particularly when it comes to harmonizing the way in which the solvency margin is calculated. It is obvious that, while ways of calculating reserves differ fundamentally from one country to the next, and while they lead to levels of prudential reserves that are substantially different, the margin requirements calculated on the basis of these reserves are very different from one country to the next - for a risk that is identical. Rules concerning asset eligibility only make matters worse - what passes for prudence in one country becomes imprudence in the country next door, as we saw with the use of derivatives to hedge assets. This situation is doubly penalizing: for one thing, it encourages companies to adopt a non-integrated approach to risk; moreover, it aggravates the fact that insurers in Europe are not playing on a level field.

The approach to risk embedded in current solvency rules is probably too cursory compared with approaches that have been developed in other parts of the world notably in the United States, with RBC, or by the rating agencies, whose models for calculating capital requirements developed the RBC model, or again in the banking industry, with Basel II. Viewed from this perspective, the European prudential approach appears to be lagging behind. However, and offsetting its cursory and hence necessarily approximate character to some degree, the European approach is fairly demanding in terms of capital. It is calculated to include, on average, an additional margin of safety.

The overly simplistic nature of the European rules has another unfortunate effect. It fails to make fine distinctions about the financial situation of the insurance company whose solvency is being assessed. From the micro-economic perspective of businesses, this means that companies in good financial shape are penalized compared to those in trouble. From the macro-economic perspective of the State as regulator, this means that shareholders' equity is badly allocated within the industry and that capital is not being channelled where the risks are greatest. In other words, the current solvency rules do not enable the European market to position itself on its efficiency frontier. With a different set of rules, the market could become more secure for the same global amount of capital invested in the industry. Experience abroad, as well as that of the rating agencies, suggests that this aim could be achieved without adding needless complexity to calculation formulas for small and mid-sized insurance companies.

Finally, the current solvency rules do not sufficiently capture the reality of insurance groups. Additional supervision of groups has been added to solo surveillance by integrating just one characteristic aspect of such groups: the dual use of shareholders' equity, that is, the fact that a group's real level of shareholders' equity is not equal to the sum of the shareholders' equity of the parent company and each of the subsidiaries that make up the group, to the extent that the equity interest of the parent in its own subsidiaries cannot be counted as shareholders' equity unless it is allocated to the shareholders' equity of the parent company. Two other aspects that characterize groups should also be taken into consideration: (i) the possibility of higher operational risk if the systems of internal control are not adequately beefed up, to reflect the fact that a group is more difficult to steer and control than a stand-alone enterprise; and (ii) the geographic and business diversification that group organization enables and 
that leads to a global risk that is smaller than the sum of the individual risks that comprise it.

\section{The importance of an open reform process}

It is no longer possible to think that a market activity like insurance can be reformed behind closed doors, as it was in the past. For this very reason, the reform process initiated by the European Commission is intended to be an open one.

\section{(a) Insurance regulation can no longer be imposed from the outside}

The insurance market is becoming increasingly complex. In addition to this growing complexity, it is evolving very rapidly. For these reasons, public policymakers and the regulators who supervise the industry are finding it increasingly difficult to grasp the growing subtleties of the insurance business. To cite just one example, recall the reluctance of regulators - not to say their outright opposition - to the use of derivatives to hedge insurance assets, until the crisis of 2002, when the financial community discovered to its astonishment that the assets of a number of insurance companies were woefully underprotected and that the main reason was that public policymakers were clinging to the quaint notion that insurers lacked the necessary sophistication to properly manage instruments of this type. Unless the market and the regulatory and supervisory authorities reach some kind of consensus, it is difficult to imagine effective solvency reform.

This consensus is all the more vital in that the added value policymakers can bring to the workings of the insurance market is clearly delineated. As long as insurance companies are in good financial shape, which is true for the overwhelming majority of them today, the interests of three major stakeholders - management, shareholders and policyholders - are perfectly convergent. Indeed, it is difficult to imagine a more efficient mechanism than the market itself for converging these interests and satisfying policyholder interests. Under the circumstances, any ill-advised intervention on the part of industry supervisors - even the most well-intentioned - can only jeopardize the financial strength of the companies in question and weigh adversely on policyholder interests over the medium term. Things are different when insurance companies are not financially sound: in such cases, protective action on the part of supervisory authorities is essential. In other words, both the market and supervision are equally legitimate when it comes to protecting policyholder interests, and it is only by achieving cooperation and consensus that new and more effective solvency rules will emerge.

The trend toward more complex business organizations, with the emergence of large groups and financial conglomerates, as well as more demanding markets, has made traditional techniques of supervision - onsite review of physical supporting documents - increasingly obsolete, especially in light of the proliferation of innovations in the design of investment products and insurance coverage, not to mention the strides made in financial analysis, notably the development of internal models, which has enabled a much more demanding approach to solvency. The Federal Reserve recently demonstrated that the stock market was a much better leading indicator of how U.S. 
banks are performing than supervisory assessments of banks, and that the latter could learn a thing or two from the former. ${ }^{1}$ Hence, a full array of more or less major adjustments could be introduced to modernize the way insurance company solvency is assessed and, in so doing, enhance its efficiency. Indeed, these adjustments have become possible or necessary in light of recent developments.

\section{(b) Stakeholders in the Solvency II process}

The European Commission, which is piloting the project, is "adamant" on this point. All "stakeholders" in this reform must be able to offer their contribution to ensure that nothing of importance is overlooked. Consequently, the contributions will be very diverse.

Via their industry organizations - in particular, the Comité Européen des Assurances (CEA) - insurance professionals will contribute the knowledge of experts who know the markets, the workings of insurance companies and risk measurement and management techniques. Their contribution is all the more important in that they are clearly the stakeholder whose interests converge most immediately with the interests of consumers, as we have seen. Alongside insurance professionals, we find subject experts such as actuaries, who play a central role in the evolution of risk management techniques within companies, and whose input, via the International Actuarial Association and the European Forum of Chief Risk Officer (CRO Forum), will be fundamental on the most technical issues.

Insurance supervisors represent another source of insurance expertise. They too offer the wisdom of experts, having often dealt with insurance companies undergoing financial difficulty. In addition, they are adept at protecting the interests of policyholders when this happens. The International Association of Insurance Supervisors (IAIS), through its guidelines and principles, will have an influence on the content of the reform, in line with the stated objective of the Commission in its Framework for Solvency II. However, because its relative lack of experience has not permitted it to play a role that compares with that of the Basel Committee, the IAIS should take a backseat to European regulators and supervisors. In connection with the Lamfalussy approach that is being applied to the draft Solvency II directive, it constitutes the centrepiece in the conception of the reform, via CEIOPS (Committee of European Insurance and Occupational Pensions Supervisors, level 3 in Lamfalussy procedure terminology) and EIOPC (European Insurance and Occupational Pensions Committee, level 2 in the Lamfalussy terminology).

Alongside insurance regulators and supervisors, consumer protection groups are also being asked to provide input as the guardians of policyholder interests.

This dialogue between stakeholders and the European Commission, which, along with the Council of Ministers and the European Parliament, is the ultimate arbiter, will serve as the basis for a balanced and comprehensive reform of insurance company solvency. The responses to this round of questioning will be synthesized by the European Commission, whose goal is to draw up a draft version of the directive by

\footnotetext{
${ }^{1}$ See Berger et al. (2000) and Gunther et al. (2001).
} 
early 2007. This draft will be submitted to EIOPC and to industry professionals as well to the experts. It is only after all of these steps have been completed that the project will be submitted to the Council and the European Parliament, as part of a co-decision procedure whereby adoption requires the consent of the Commission, the Council and Parliament.

\section{The principal orientations of Solvency II}

Admittedly, it is difficult to define orientations for the reform when discussions between the various stakeholders are only just beginning and the divergence of their positions is at a maximum. However, it is possible at this stage to specify the initial orientations, which, while they do not meet with unanimous approval, have acquired broad consensus among both academics and members of the European insurance industry and among many insurance supervisors.

The reform should seek a reasonable trade-off between security and wise/prudent use of capital

Indeed, capital is a scarce commodity that all sectors of the economy seek to attract and retain. Every euro that is invested in the insurance industry is a euro that will not be invested elsewhere in the economy. This is true for all regulated financial sectors. Consequently, the level of capital that public policymakers decide is necessary for the insurance business, to the extent that it will be immobilized in this sector at the expense of other sectors, is no simple micro-economic matter. It is first and foremost a macroeconomic decision made by economic policymakers, with an impact on growth and development.

Because it is a scarce resource, capital is also a costly one, which requires the payment of a risk premium over the risk-free rate of return. As a result of recent financial turbulence, this risk premium has been pushed up sharply in all markets. In the insurance sector, the risk premium has been drifting upward since the beginning of the 1990s due to the growing perception that both life and property/casualty insurance are volatile industries, more volatile than average in any case.

It is imperative that the new solvency rules make efficient and economical use of capital. These new rules must also take account of recent evolutions, which have led to more complex organizational structures for insurance companies as the latter have regrouped, to greater levels of responsibility, to new market standards, and to the higher cost of capital. This in turn presupposes:

- striking the right balance between security and economy, it being the case that the current level of insurance company capital proved to be sufficient to enable the industry to survive the shock of the early 2000s without any major bankruptcies;

- modernizing the system of supervision, which should give a more prominent place to external supervision of internal control compared with traditional control of operations;

- applying a method of cost-effectiveness analysis in order to define new rules that will help to avoid tying up too much capital in insurance at too high a cost; 
- developing a comprehensive approach to risk, in order to impose solvency requirements that make reality-based discriminations.

The solvency margin must serve as a shock absorber rather than a brutal axe

Corporate finance theory teaches us that, in general, the purpose of shareholders' equity is to allow the business to absorb unexpected shocks that cannot reasonably be integrated into the calculation of its reserve requirements. And, for this reason, solvency margin requirements only make good economic sense if they seek to ensure that companies have a sufficiently thick capital cushion for this purpose, provided that certain restatements are made to ensure a more judicious measurement of this capital. It should therefore be possible for insurers to use the solvency margin to absorb truly exceptional shocks and surmount difficulties that are largely unforeseeable. It should not be used as an axe that automatically authorizes supervisors to declare a death sentence for the companies concerned.

As a corollary, the solvency margin requirement must not in and of itself be an inviolable threshold. Moreover, insurers must be given a reasonable timeframe neither too short nor too long - over which to rebuild their margin if they have been pushed over the threshold by unforeseeable events.

It also presupposes that we evolve toward a more comprehensive conception of prudential capital, which is defined by a specific function, that is, its capacity to absorb shocks in general and losses in particular. This differentiates it quite clearly from conventional capital, which seeks to structure the decision-making power in joint stock companies. This capacity to absorb is found not only in conventional capital but also in more hybrid forms, explicitly in super-subordinated securities, and implicitly in the securitization of insurance liabilities. These two examples, which are not exhaustive, could be completed by a number of other financing innovations. By definition, this list of innovations should remain open, it being up to supervisors to ascertain whether these innovations correspond to the prudential definition of capital as shock absorber.

Supervision should be proportioned on the basis of the financial condition of the insurer, and particularly on the basis of the level of its solvency margin

One of the biggest criticisms of the current rules of supervision is that they do not in any way take into account the insurer's global risk profile: the required margin is the same for all, independently of the real nature of the insurer's risks. The discretionary power of the supervisors is as invasive with respect to financially sound insurers as to those in financial difficulty. Admittedly, certain graduated responses have recently been introduced with the application of European Solvency I directives. When supervisory authorities deem that policyholder rights are threatened, they may demand that a financial recovery program be prepared and, on the basis of the latter, may raise the solvency margin bar. But clearly, it is necessary to go further in the attempt to adjust the powers entrusted to supervisory authorities to the real financial situation of the enterprise. 
Indeed, this situation is absolutely fundamental in the interest of protecting policyholders, which is, by definition, the very aim of supervision in the first place. The role of supervisory authorities is to "represent policyholder interests." Viewed from this perspective, both the prudential regulation and supervision of the insurance industry can be seen as mechanisms for optimizing the governance of insurance companies. Prudential supervision should, however, make an effort to interfere as little as possible in the management of financially sound insurance companies, which is to say most insurance companies in business today. In well-run and financially sound insurance companies, the interests of management and shareholders converge with those of policyholders, leaving little room for supervision to add much value. All forms of systematic intervention on the part of supervisory authorities can only be inefficient and, above all, counterproductive, at the expense of both the insurance company and the policyholder. There is no economic, theoretical or empirical basis for systematic intervention of this type. ${ }^{2}$

Since the level of its solvency margin is arguably the best indicator of its ability to resist, supervision should match this level. This proportionality can be introduced in a variety of ways, with a larger or smaller dose of discretionary power and related supervisory power.

Today, the discussion seems to be pragmatically focused on a dual solvency threshold, with the idea that the upper threshold (SCR) would serve as a target to be reached within a reasonable timeframe, whereas the lower threshold would be an absolute minimum. Below this lower threshold, the supervisor would be broadly empowered to ensure that policyholder interests are safeguarded. Conversely, over and above the upper threshold, supervisory power would be reduced, so that the market can function optimally and avoid interference in the natural process of convergence between the interests of the insurer and those of its policyholders.

The new standard formula should take into account the principal risks, and also be easy to apply

Based exclusively on reserves and premiums, the current formula for calculating the solvency margin is overly simplistic because it only considers one risk - the underwriting risk. Admittedly, some other aspects of risk may be taken into account by ad hoc mechanisms whose consistency remains to be demonstrated, other risk categories are totally ignored, and others are counted twice rather than once. Oddly enough, diversification and pooling - which are two of the central pillars of the insurance business (indeed, insurance is unthinkable without them) - have no place whatsoever in the prudential construction of insurance. As a result of this oversight, the current solvency requirement makes no real distinction between insurance companies based on their actual exposure to risk.

A broad degree of consensus has been achieved, both within the industry and among supervisory authorities, around the idea that the future formula for calculating the solvency margin requirement should no longer be lump-sum, as is the case today.

\footnotetext{
${ }^{2}$ See Rochet (2002).
} 
Instead, it should be risk-based - that is, it should systematically take into account the principal risks to which the insurers in question are generally confronted, particularly underwriting risk, interest-rate risk, market risk and asset liability mismatch risk. This would enable the use of a more discriminating formula that achieves a better match between capital requirements and the reality of risks. It would also provide an objective basis for matching supervision to the actual risk exposure of the particular business. The sacrifice of simplicity would be offset by the optimal distribution of capital among insurers. At the same time, it is important to ensure that less simplicity does not make the formula too difficult to manage. Some supervisors remain reluctant to integrate either diversification or pooling into the solvency assessment, despite its fundamental role in insurance company exposure to risk.

It is important to take great care in devising the standard formula that will probably be used by most insurance companies. This will require making use of the body of technical work that has been accumulated in recent years, largely inspired by modelling tools developed recently for the purpose of isolating a few parameters that play a decisive role in the assessment of a company's global risk and in calculating the optimal level of the economic capital. In any case, we are not starting from scratch. Risk-based formulas are already being used in numerous countries and by some rating agencies. Their primary shortcoming is that, like the American RBC formula, they do not take asset liability matching or risk diversification into account at all. Recent experience with internal models should nonetheless help us to enhance existing RBCtype formulas in these two respects, naturally, without detracting from the formula's manageability.

\section{The reform must acknowledge the legitimacy of using internal models for calculating prudential capital requirements}

Internal models, including those that feature a certain degree of modularity, enable insurers to acquire a more integrated and coherent vision of their risks. They give their users greater knowledge of and ability to manage their risks than any other instrument, particularly any sort of standard formula. It is therefore natural to ask whether insurance companies that use these internal models may use them to calculate their prudential capital requirements - provided that these models meet an independently defined quality standard and that they are recognized by company management as a synthetic risk management tool. In addition, internal models can be upgraded over time.

Conversely, it is obvious that, like all quantified models, they contain a number of uncertainties (model risk), and that insurance companies are not on an equal footing when it comes to their ability to use them. The issue of the empirical validation of these models is also a critical one, and probably far more complex than in the banking industry due to the multidimensional nature of the risks to which insurance companies are exposed. Financial risk is only one dimension for insurers, and not necessarily the most uncertain. Therefore, technical standards for validating these models will have to be devised and they will have to be adapted for use in insurance supervision. It will also be necessary to develop standards that specify the other than technical conditions 
under which companies will be allowed to use these models: what place should such models have in company management in general and in corporate governance in particular? To what extent should we allow the results of the standard model to serve as a substitute for those generated by the standard formula? In other words, under what circumstances should we require a return to the standard formula?

Even if a relative consensus has been achieved among professionals, regulators and supervisors on this point, it is also true that some of them still feel that no internal model is fully operational to date and that the model risk is too great to justify lowering solvency margin requirements. The first argument is clearly not valid, judging from what is available in the market today. As for the second argument, it is contestable to the extent that the model risk also applies to standard formulas (any standard formula makes implicit reference to an ultra-simplified model) and they are always less discriminating than internal models (a given level of capital corresponding in all cases to a higher risk level for the market). What is certain, on the other hand, is that the conditions under which internal models are validated must be given thorough consideration by all experts, which presupposes an in-depth discussion among professionals that includes actuaries, regulators and supervisors.

For groups, solvency supervision should be conducted with the group effects included in the assessment

All of the empirical work conducted to date on the subject demonstrates that taking group effects into account, whether in terms of the benefits of diversification or financial risk factors - in particular, the risk of contagion that this type of structure is exposed to in the event of financial difficulties - modifies substantially the assessment of the level of risk of the entities of the group and hence the level of capital required to cover them. Naturally, the group should be assessed not on the basis of its domestic operations, but on the basis of its European scope, which corresponds to the single market and area within which insurers compete. These effects can be directly taken into account by substituting solvency supervision at the group level for solvency supervision at the level of each entity considered individually. They can also be taken into account indirectly, by allocating group effects to the various entities that comprise the group on the basis of their marginal contribution to these effects or, more simply, on the basis of their share in the group's equity capital or revenues.

Nonetheless, numerous regulators and supervisors continue to defend the primacy of the individual entity level approach, arguing that because it is the entity that underwrites the risk (and not the group as a whole), it is responsible for meeting the performance obligations set forth in the policy. But although this argument is bulletproof from a legal point of view, it is only relevant financially for groups that are in financial difficulty. In this case, the "every man for himself" rule is more likely to apply when things are going well, especially since domestic supervisory authorities will encourage the companies concerned. Naturally, the magnitude of this risk depends on rules and guarantees that structure the relationships between members of the same group of companies, and in particular between the parent company and its subsidiaries. Moreover, in cases where these rules leave room for uncertainty 
as to the degree of solidarity between the various entities of the group, it is always possible to stipulate that in the absence of adequate rules and guarantees of this sort, or if the group falls below a certain level of solvency, then supervisory power will be reinforced.

The nature and extent of the guarantees given by the parent company with respect to the transferability of funds in the event one of its insurance subsidiaries finds itself in financial difficulty should therefore constitute one of the keys for assessing group effects at the subsidiary level or for substituting group level supervision for supervision at the individual company level.

\section{The salient issues in the current debate}

We will review the principles of the Commission's Framework as well as the principal points of discussion with CEIOPS, in light of the responses to the first two rounds of questions.

\section{The principles of the Commission's Framework}

The Framework for Solvency II can be summed up by the following seven principles, which (except for the sixth, in its reserve assessment dimension) respond fairly well to the concerns expressed by industry professionals:

- Compatibility of the process with the IAS process, for assets as well as liabilities, which must be measured at their fair value for margin calculation purposes.

- Recognition of internal models, which may lead to capital requirements that are lower than those derived using the standard formula.

- Application of the principle of a risk-based standard formula, instead of the current one, for the calculation of the required margin, for which internal models could be used as a substitute.

- Under conditions that remain to be defined, the factoring in of business diversification, both inter-segment and inter-group.

- Introduction of proportional supervision via a two-tiered solvency margin: a required minimum (MCR) and a target margin (SCR).

- The SCR would be calculated so that in 99.5 per cent of all possible situations, assets cover reserves, which themselves are measured with a probability of 75 per cent.

- Harmonization not only of solvency rules but also of the practice of supervision, under conditions that remain to be defined.

\section{Issues being debated with CEIOPS}

Solvency II has now entered into its active phase. The Commission sent CEIOPS three waves of questions, with the stated request that it consult as broadly as possible on these questions with industry professionals:

- The first wave, which is very general, was devoted to the internal and external control of insurance companies and to asset management principles. 
- The second wave was concerned with the prudential amount of reserves, the required level of capital, group solvency, risk hedging techniques, supervisory power and future impact studies.

- The third wave, which is pending, focuses on assets that are eligible to cover the solvency margin, supervisory cooperation, reporting, the procyclicality of prudential systems and the treatment of small insurance undertakings.

Several points of the CEIOPS position have come in for criticism. Others are still being debated within the insurance industry. Below, we will focus on the seven key issues pending at this stage in the discussion.

\section{(a) Desired overall prudence or the target margin (SCR)}

To harmonize the approach to solvency among insurance companies that have underwritten different risks, and among countries that have different market characteristics, it is necessary to find a common yardstick for measuring this solvency that is independent with respect to all.

The yardstick that was unanimously deemed to be the most appropriate is value at risk (VAR). VAR, widely used in the banking industry and familiar to insurers through the use of internal models, measures the amount over a specified horizon and confidence interval (or target probability level) that a company's losses will not exceed. If the company in question has shareholders' equity that is equal to this upper limit on loss, we may conclude, with the specified confidence interval, that it will survive for the specified horizon of time. In other words, once we know the amount of the company's liabilities and have set a minimum probability target for its survival (or a maximum probability target of ruin), it is possible to deduce the amount of capital that is required to ensure that its assets cover its obligations, with the specified probability and over the specified horizon. This is defined as the minimum amount required to ensure with a sufficient degree of probability that the insurer will remain solvent. It corresponds to the capital solvency requirement.

Consequently, the critical question is that of calibrating the probability of ruin and the horizon over which this probability should be assessed. In truth, no analytic arguments enable us to choose one hypothesis over another. By definition, both the probability and the horizon over which it is measured are arbitrary choices. In the interest of staying in business, however, companies will be tempted to decide on the basis of their brand strategy. In all financial services sectors, the inevitable involvement of the regulator leads to the imposition of a floor on the choices that are open to the company. Regulators have often been inclined to favour a probability of ruin that is close to 0 per cent - or to maintain sufficient ambiguity around this 0 per cent. For this reason, many observers reasonably assume that this is the implicit target of policymakers. Naturally, this attitude runs the risk of opacity, encouraging the markets to believe that there is no probability of ruin, even though this is technically impossible, since it would imply, by definition, an infinite solvency margin - in other words, the disappearance of insurance and a return to self-insurance. In addition, this attitude and the opacity that it has engendered have unfortunately helped to maintain a good deal of arbitrariness in the actual constraints imposed on various companies. 
Wisely, the European Commission wanted to rule out this attitude by specifying, as we have seen, that the future solvency rules should seek a solvency capital requirement (SCR) that puts the probability of ruin at 0.5 per cent over a 1 -year horizon. There was no real opposition to this figure, because it corresponds to the probability that an issuer with an investment grade rating will become insolvent. Indeed, there is no other justification. For the French market, this target is perfectly reasonable. However, bear in mind that this is an experts' number, and its sole justification is pragmatic. Its macro-economic coherency, which is nonetheless essential as far as medium- to longterm sustainability is concerned, has been neither tested nor debated. Consequently, it is too early to conclude that discussion on this issue is closed.

\section{(b) The prudence of technical provisions}

This 0.5 per cent probability of ruin is, however, purely nominalist. It does not apply to the flow of funds until all of the insurer's obligations have been met, but rather to the discounted value of its future liabilities as they can be estimated in 1 year: its assets must cover provisions in 99.5 per cent of all imaginable situations in 1 year. This is a pure accounting criterion: the severity of this 99.5 per cent probability depends on the level of provisions - that is, the degree of prudence with which they have been estimated. The more prudently they have been estimated, the higher the level of required capital, which may at first glance seem contradictory.

In principle, Solvency II reform must be IAS-compatible, which means that the level of reserves used to calculate the solvency margin should be IAS-compliant reserves. However, the IAS Board has not yet published the accounting standard for insurance liabilities and liabilities with profit-participation mechanisms, which is the case of most life insurance contracts sold in Europe. We can therefore do no more than venture a guess as to what might be the fair value of an insurance contract which, once it has been written and purchased, cannot be traded on any open market. Admittedly, insurers generally have some idea of the actuarial expectation or best estimate value of their contracts. They are in a position to calculate the present value of the actuarial expectation of their future cash flows. On the other hand, we are far less clear on the margin for risk and uncertainty that should be added to this actuarial expectation to obtain a more accurate value for these contracts. Another way of putting the same question is to ask oneself what level of risk premium should be used in the discount rate for the actuarial expectation of the future cash flows of contracts.

As we have seen, the Commission has suggested - while confessing that its suggestion is arbitrary - that a margin of 50 per cent be used at this stage to cover 75 per cent of all possible situations imaginable, instead of 50 per cent for best estimate figures. Some members of CEIOPS feel it would be more prudent to raise the margin to as high as 80 per cent to cover 90 per cent of all possible situations imaginable. The CRO Forum suggests a margin of 20 per cent that would be adequate to cover 60 per cent of all possible situations imaginable, claiming that this figure, which is derived from the risk premium on shareholders' equity, comes closer to reflecting a marketderived margin. The IAS Board would probably be tempted to refer to what the exchange value could be between two willing partners (who are both insurers). Reconstituting a market value, even in the absence of a real market, is a problem that 
economists are both familiar with and capable of managing. ${ }^{3}$ At the same time, this reference poses a major problem in that any such value would necessarily include the cost of shareholders' equity required to enable an insurer to resume responsibility for these obligations, and it is this very same shareholders' equity that we are trying to calculate. The estimated provision for the purpose of calculating solvency margin requirements must exclude the cost of shareholders' equity needed to cover these requirements.

Via the CEA, the insurance industry is arguing for adoption of the best estimate approach. The reason is not just pragmatic, although it would facilitate adaptation to what the IAS Board will ultimately decide for the accounting treatment of insurance liabilities. It is also and above all economic and financial. ${ }^{4}$ According to the ArrowLind Theorem, ${ }^{5}$ when the risk of a project is not correlated with the macro-economic risk (which we can consider to be the case with guaranteed rates in life insurance and in property-casualty insurance more generally), then the project in question must be assessed as "risk neutral," that is, using an actuarial expectation and a discount rate equal to the risk-free rate. On the other hand, if the project's risk is positively correlated with the macro-economic risk, or if - as with some catastrophic risks - it is not diversifiable or is not derived from a well-known law of distribution, ${ }^{6}$ it is necessary to integrate a risk premium that reduces the discounted value of future profits. It is clearly in this direction that a financially sound solution to this debate should be sought.

\section{(c) The minimum capital requirement}

In its Framework for Consultation, the European Commission did not give any particular guidance on this subject. CEIOPS is leaning in the direction of an MCR calculated in the same way as the current solvency margin, at least temporarily. What is paradoxical about its position is that it would probably render the debate about the SCR meaningless, casting doubt on the philosophy of the two-tiered margin, because it would most likely lead to an MCR that is only 25 per cent lower than the SCR evaluated with a probability of 99.5 per cent. In addition, it is hard to see the economic or financial rationality of calculating the MCR on a much more frustrating basis and, above all, much less revealing of the risk of the business, than the basis used to calculate the SCR. On this assumption, the desire for simplicity would clearly lead to the exact opposite of what we're striving for, that is, a more risk-based approach.

These, in fact, are the reasons why the insurance industry is against the solution put forth by CEIOPS. In the interest of maintaining a solution that is simple, based on a

\footnotetext{
${ }^{3}$ See the classical problem of evaluating the access of competitors to network infrastructures held by a dominant operator, in general a formerly state-owned enterprise (telecommunications, electricity and rail transport).

${ }^{4}$ This crucial point has been highlighted and developed by Christian Gollier in his work on risk under the auspices of the Institut de développement économique de Toulouse (IDEI). For example, see Gollier (2002). For the full analysis below, we refer to this economist's work.

${ }_{6}^{5}$ Arrow and Lind (1970).

${ }^{6}$ See, in particular, Gollier (2005).
} 
more realistic assessment of the risks of the insurance business, and faithful to the spirit of the two-tiered margin philosophy, the insurance industry is suggesting that the margin be calculated as a proportion of the SCR (50 per cent of it). Some industry professionals have also mentioned the possibility of calculating the MCR using internal models. Given that the MCR is only a constraint for companies whose financial situation has seriously deteriorated, we can nonetheless ask if this latter solution would not come up against the question of the reliability of the internal model used by the insurance company. At the very least, we might wonder about the reliability with which the insurance company used its internal model if doing so did not allow it to avoid falling into serious financial difficulty and getting dangerously close to the MCR.

\section{(d) Covering the margin}

Is it necessary to regulate which assets are eligible to cover capital requirements? Opinions on this matter diverge. Even within CEIOPS divergence exists. Some members consider that merely requiring a certain level of assets to cover the margin is enough, while others would like to see a list of eligible assets imposed. The insurance industry is opposed to the introduction of a list of eligible assets, because it runs counter to a risk-based approach to solvency, which is based on capital loading for at-risk assets. There is probably greater potential support on both sides for the adoption of a "negative" list, which would merely exclude certain assets deemed too risky.

\section{(e) The structure of the standard formula}

Existing risk-based formulas can be divided into two families. The first family, that containing factor-based formulas, applies set capital loading coefficients to different bases or factors derived from accounting data and thought to measure the company's level of exposure to various risks. The American RBC and the Standard \& Poor's model are members of this family. The second family, that containing scenario-based formulas, measures the impact of various stresses (scenarios or stress tests) applied to the balance sheet of insurers and applies a capital loading coefficient that can go up to 1.00 to various valuation variances that are generated. Both British and Swiss solvency requirements are based on this approach.

At this stage, debate is raging within CEIOPS on this issue, while both the insurance industry and the CEA have opted for a compromise that combines the two formulas that is, simple factors for most risks and scenarios or stress tests for more complex risks, such as catastrophic or asset liability mismatch risks. In fact, the insurance industry would like the standard formula, whatever it turns out to be, to integrate at least some asset-liability matching, since in the insurance business the risk associated with an asset can only be gauged by looking at the liability that it is intended to cover. A highly volatile asset is not a risk for the insurer if its volatility is strongly and positively correlated with that of the asset it is matched against. Therefore, the insurance industry quite understandably favours capital loading for the asset-liability mismatch rather than for the volatility of the asset. Naturally, this argument does not apply to the credit risk of assets, which must be loaded as such because it bears little or no relation to liability fluctuations. 
Incidentally, this approach would allow us to resolve the special case of how equities should be treated by the same token. The risk-based formulas in force penalize equities because they are by nature more volatile than bonds and are hence considered to be more risky. This penalty has serious consequences for the financing of modern economies, and explains why U.S. insurers no longer hold many equities at all. However, equities do not just serve the purpose of offering higher returns at higher risk, which would justify greater capital loading. They also serve to cover the longterm obligations of insurers. The market for bonds with longer than 10-year maturities is simply not very liquid, and there is even less of a market for inflation-linked bonds. Without a doubt, equities offer the best coverage for long-term obligations. For this reason, it is not the fact that equities are held that should be penalized, but rather the fact that a badly managed equity investment policy can lead to an asset-liability mismatch problem.

\section{(f) Discretionary supervision}

The debate centres on the degree of empowerment that supervisors should be given, for example in revising solvency requirements upward depending on the insurance company's financial condition and the types of risks it covers or to impose higher standards of prudence to the assessment of certain balance sheet items.

The interests of the various stakeholders do not necessarily converge on this point not because they have different prudential philosophies, since the latter should be tending toward convergence to the extent that the economic and financial fundamentals that underlie them have also converged in recent years - but rather due to different legal and administrative traditions. Continental Europe in general, and France in particular, tend to accord a prominent place to codified law and procedure, whereas the Anglo-Saxon countries tend to prefer a pragmatic marketplace approach based on consensus between policymakers and businesses.

Not surprisingly, CEIOPS feels more comfortable with broad discretionary powers. And consistent with their legal and administrative traditions, insurers in the U.K. and the Scandinavian countries tend to favour broad discretionary power for supervisory authorities. Insurance professionals in Continental Europe would like to see these powers clearly delineated, and hope that they will be more restricted with respect to financially sound insurers, particularly when the solvency margin is above the SCR.

\section{(g) The credit risk of reinsurers supervised in Europe}

In a universe where reinsurance is not supervised, it is obvious that the reinsurer's credit risk should be a key factor in assessing the insurer's reinsurance receivables. In a universe where reinsurance is supervised in Europe, and in which reinsurers must meet investment grade solvency requirements (probability of ruin equal to or less than 0.5 per cent), the internal logic of prudential supervision is that no capital loading be imposed on reinsurers subject to European supervision in terms of their credit risk. This same logic should apply to insurance subsidiaries.

As a backdrop to these orientations, it is necessary to consider the need to complete work on the single European insurance market, a task that has been impossible due to the patchwork of domestic regulations and supervision. Solvency II reform should 
therefore also culminate in much greater harmony in terms of regulation and supervision in Europe. What form should this harmonization take? The future directive should certainly aim for maximum rather than minimum harmony. But it is probably necessary to go further and provide for procedures aimed at harmonizing supervisory practices. In this area, the field of possibility is vast, from the implementation of coordination procedures to the creation of a European system of insurance supervision, like the European central bank system. Among other things, the response depends on the nature of what is being harmonized and could very well be modular, depending on whether we are talking about calculating reserves, validating internal models or the integrated supervision of insurance groups.

\section{References}

Arrow, K.J. and Lind, R.C. (1970) 'Uncertainty and evaluation of public investment decision', Quarterly Journal of Economics 60(3): 364-378.

Berger, A., Davies, S. and Flannery, M. (2000) 'Comparing market and supervisory assessments of bank performance: who knows what and when?', Journal of Money, Credit and Banking 32(3, Part II): 641-667.

Gollier, C. (2002) Economics of Risk and Time, Cambridge, MA: MIT Press.

Gollier, C. (2005) Does ambiguity aversion reinforce risk aversion? Applications to portfolio choices and asset prices, IDEI working paper, IDEI, Toulouse, FR.

Gunther, J., Levonian, M. and Moore, R. (2001) 'Can the stock market tell bank supervisors anything they don't already know?', Economic and Financial Review 2Q, Federal Reserve Bank of Dallas, pp. 1-9.

Rochet, J.-C. (2002) When insurers go bust, IDEI working paper, IDEI, Toulouse, FR.

\section{About the Author}

Philippe Trainar is Chief Economist, Fédération Française des Sociétés d'Assurances (FFSA). 